\title{
CALF: CREATING ACADEMIC LEARNING FUTURES. A synopsis of a three year HEA-funded Project from an arts university perspective
}

\author{
Karenanne Knight (karenanne.knight@falmouth.ac.uk) \\ Falmouth University, Penryn Campus, Treliever Rd, Penryn \\ Cornwall, TR10 9FE, United Kingdom
}

\begin{abstract}
The paper discusses the introduction, development, results, conclusions and future projections of the Creating Academic Learning Futures (CALF) project, based between the University of Leicester and Falmouth University. It will encompass elements of the final report (Romenska, 201, includes feedback from staff and students involved in the project throughout and after its tenure, and reflects on the legacies of the project in terms of future learning. Incorporated within the paper is the fictional story/blog of CALF, featuring Charlie and his friends, (written as a parallel story over the three years as the project developed for the CALF blog, and as Writer/Illustrator in residence within the author's role as Project Manager). The story uses discussions and scenes from many of the events that were created, developed and experienced over the three years whilst introducing and narrating the project from a fictional perspective.
\end{abstract}

\section{Keywords: C.A.L.F.U.K; Futures; Arts; Blog;} Fiction; Learning

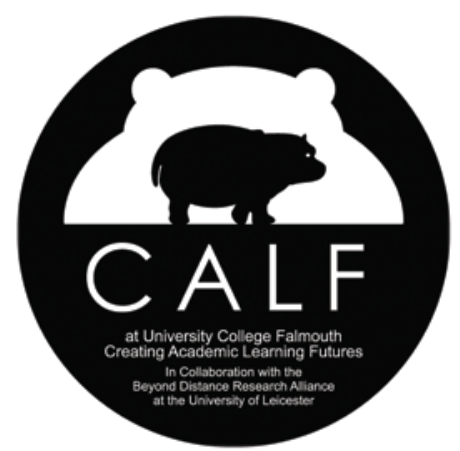

Figure 1: CALF Logo. Design by Karenanne Knight and Jane Nevin (C) Falmouth University

The CALF Research project arose and developed over a three-year period as a collaborative project between the universities of Falmouth and Leicester. Its aims were to create, explore and present for discussion a variety of plausible 'alternative futures' for learning and teaching in Higher Education. This was achieved by capturing emerging issues that might influence the future of student learning by engaging student voices.

The project had three areas of interest:

1. The factors that might influence the future of teaching and learning.

2. The ideas the two universities had concerning the futures of students.
3. The possible and preferred futures of the students who would participate in the project.

However, we found that despite the increased attention directed to the future of higher education, students were often seemingly uninvolved in policy decisions and therefore largely inactive in shaping the future of their educational processes. Few authentic voices from learners had been interpreted into feasible approaches to learning or included in projects aiming to create visions for the future of teaching and learning. Meanwhile, higher education institutions, with their natural conservatism and concern for tradition and quality, seemed to change slowly. Universities generally needed to look beyond the obvious perhaps if they were to prepare for the future in unknown and uncharted territory.

CALF investigated the idea that it would be essential to involve today's learners in a dialogue about the future of learning in order to ensure that strategies for the future of higher education should take into account changes in students' expectations and cultures. We suggested that students have unique contributions to make in the development of realistic visions and future directions and pathways for teaching and learning. The students' perspective was therefore likely to be a vital component in envisioning any possible futures for higher education. The opportunity for student representation in the efforts for constructing strategies for the future of teaching and learning would consequently seem to enable greater and more fruitful cooperation between all and many interested parties.

\section{Objectives}

The objectives agreed at the start of the project included:

- Capturing signals that might influence the future of student learning.

- Involving a wide variety of CALF contributors in developing, understanding and examining possible, preferred, viable and achievable futures for learning in HE.

- The interpretation, modelling and representation of ideas emerging from all CALF activities and secure feedback on them. 
These objectives were, with the projects aims, translated into three major research questions:

1. What factors may influence the future of teaching and learning?

2. What are their (the students) ideas about the future of students from Falmouth University and the University of Leicester?

3. What are the preferred futures of the students participating in the project?

\section{Method}

\section{Research methodology}

In total the project used a combination of four research methods in order to find answers to the research questions regarding the future of teaching and learning including horizon scanning; maximum difference scaling; scenario development and cognitive mapping.

\section{Questionnaires}

One avenue developed in order to address the CALF project aims and objectives and identify preferable futures for teaching and learning was the questionnaire. One particular questionnaire used the maximum difference scaling method.

A total of 102 questionnaires were completed by students participating in the project from a variety of courses including: BA English with Creative Writing; MA Design; MA 20 ${ }^{\text {th }}$ Century Art and Design; Medicine MBChB Year 4 and a number of post graduate and research students. The participating cohorts were asked to choose between eleven 'most important' or 'least important' option within the questionnaire. The initial instructions were:

"Imagine that it is the year 2025. Imagine that you have just finished secondary education and you are considering further study. Which of the features described in the questions below would be MOST likely to make you want to choose a university or college for further studies and which would LEAST make you want to enrol?”

Options ${ }^{1}$ that the students had to choose from when completing the questionnaire included:

- Accommodation, facilities and buildings.

- Links with employers.

- $\quad$ Period of course delivery.

- Living costs.

- The accumulation of course credits through studying abroad.

- Environmentally friendly practices.

- Face to face tutorials.

- Online access to internationally renowned teachers, practitioners and researchers.

\footnotetext{
${ }^{1}$ These options are expanded upon in the NTFS Projects Final Report (Romenska et al., 2011).
}

- $\quad$ Online tutorials and virtual reality environments at low cost.

- Guided unlimited access to internationally renowned quality learning resources.

- Personalised learning processes.

- Course and university recommendation and pastoral support.

\section{Workshops}

Students also continued to participate in a variety of workshops called CALF Creative Events throughout the three years. In total there were 320 participants in 31 workshops. This format had been chosen to enable students to develop scenarios for the future of teaching and learning based on broad, interdisciplinary, current and socially orientated questions about the future. The workshops varied from 3 hours to 3 weeks in duration. However the core scenario development part of the workshop encompassed a competitive game using Google Maps. $^{2}$

\section{Interviews}

Students participated in cognitive mapping and subsequently cognitive mapping interviews in order to uncover their ideas regarding the future. These provided rich material for the interpretation and modelling of networks of key concepts about the future of teaching and learning.

\section{The development of a "futures" model}

A "Learning Futures" model was developed and implemented in the form of the creative events already outlined. The model is best described in terms of its four components: Hindsight; Insight; Foresight and Learning Oversight. These components became the basis of the workshop activities with the aim of encouraging creativity, collaboration and learning. The students participated in group exercises that included all of these components, using technologies such as wikis; Google Maps; Google Docs; blogs; Second Life and social networking, i.e. Twitter.

\section{Events}

There were several events held throughout the three years. These varied in both duration and setting. Some events developed out of initial discussions and were student led. The second dance/technology event within the project for instance, was formed out of a dance/technology play week where students were encouraged to experiment with technology and dance. Everything achieved at this event was highlighted in the dance workspace, however, there was much excitement

\footnotetext{
${ }^{2}$ Screenshots of the Google Map Calf Game can be found in the NTFS Project Final Report (Romenska et al., 2011).
} 
concerning the technology the students had used and wanted to develop so this formed a third event the following year.

\section{Blog}

Throughout the three years we wanted to record the ongoing issues and development of the project. We decided to do this through two quite separate blogs. The first blog recorded the many events, workshops, results and conclusions within the project. The second was a creative blog.

As a lecturer in Illustration and Creative Writing at the University of Falmouth I was asked to be the Writer and Illustrator in Residence for the CALF project. I wanted to develop a fictional response to the project yet based on the many events, ideas, discussions, workshops and issues we encountered.

I decided to take the symbol of the project, the CALF or baby hippo, as a starting point and have included the initial four chapters of the blog to give the reader of this paper an insight into the parallel story of CALF. ${ }^{3}$

\section{CALF: The story of six baby hippos and their future dreams.}

\section{Prologue 1}

The CALF project is the beginning of a long, three-year journey and an exciting story. It begins as all good stories did...once upon a time...but this is not a historical study of the past, important as that is. This is the beginning of the future, a future that understands and takes on board the past but is searching for new beginnings, developing academic learning futures with and for today's students, whilst forecasting future learning for tomorrow's under- and post graduates and generations of learners to come.

So let us start the story again...

"Humph! Hummmmph!”

The baby hippo grumbled and groaned contentedly as he basked in the midday sun, dreaming of all the things he would like to do when he grew up, things his Mum and Dad could never have ever envisaged for their child. As he soaked up the sun's rays, he thought about what he could do, if only he had the chance. Little did he know he would become the icon, the logo of future learning.

The teenage hippo loved the vast, wild spaces of his homeland. He knew such a lot, yet had a tremendous thirst to understand more.

"The world is yours and dreams can come true," said his mother softly, "but you must work hard and take all the opportunities life may offer you. It is up to you to shape your future,” she

\footnotetext{
${ }^{3}$ To read the eighteen chapters that make up the complete “Story of CALF” see Knight (2016).
}

warned. The little hippo considered his mother's words.

"If I could forecast that future and guide my learning, I know I might live my dreams,” he whispered. "But through whom, and how?"

The Beyond Distance Research Alliance at the University of Leicester heard the hippo's call and in collaboration with their partners at Falmouth University (a centre of learning and excellence in the Arts in a county called Cornwall, in the far South West of the United Kingdom), decided to make his dreams come true. Whilst it might never be possible to predict the exact future of the little hippo, they knew they might stand a good chance of forecasting the possibilities and maybe even some probabilities in Creating Academic Learning Futures for him and generations after him.

This is where the story begins...

\section{Prologue 2}

Charlie, our little calf, and his five friends Henry, Sara, Izzy, Billy and Olivia looked up expectantly.

"Why don't you study here?" chortled Horatio, the eldest and most respected Hippo. "Many a qualification was gained studying from distant lands."

"But I want to design and develop the most wonderful landscapes,” chuntered Charlie. "How can I do that here?"

"I'm an artist, I want to study fine art. I have to go,” exclaimed Sara.

“... and I'm a dancer I can't dance here," muttered Olivia.

"I want to illustrate the finest magazines and books,” whispered Izzy.

"And I," growled Billy, "will produce documentaries and broadcast them across the whole world."

“... and maybe, just maybe I could be a journalist one day,” stuttered Henry.

"Then you must go and find your dreams," whispered wise, old Horatio. "One day we may all study from a distance, who knows? For now though, you must find out what learning pathways there are, for your immediate future and the futures of those who might want to follow you. Only that way will you achieve those dreams."

The little hippos pondered on Horatio's advice.

However, it wasn't long before they were on an exciting journey, a journey into the future of learning, where predictions were less likely but possibilities were endless.

\section{Prologue 3}

We don't see many hippos in Falmouth! However, a large hungry baby hippo and his friends are now knocking on many a door and asking lots of questions. Can we forecast future 
learning? What is the future of education? What are the future tools of education?

These were some of the many questions that the little hippos were chewing upon at the seaside University of the Arts. They had heard about the Beyond Distance Research Alliance and the wonderful things that were happening there. If the cheetahs, the impalas and the seals were developing their interests in this academic world then why couldn't the hippos too? Why, there was even a zoo; they would have somewhere to stay where they could discuss their dreams with others, who thought just like them. Bringing together each of the schools at Falmouth University with a course or two from each and very enthusiastic course leaders, the project began.

\section{Chapter 1: Olivia's Story}

Olivia danced and danced. She enjoyed every moment of her studies. Hour after hour were spent in the dance studio, exploring this and developing that.

"I only feel free when I dance!” she exclaimed. "I can be anyone and anything I wish, a free spirit. The music carries me, moves me, the music is within me."

Hour after hour. Day after day. Weeks moved to months and the seasons came and went as Olivia's lean and muscular frame was honed to perfection, moving from one ambition to another, achieving her goals, carrying her onwards towards her dream.

There was one dream that still seemed unattainable. She yearned to choreograph dance for the film industry, but in a way she wasn't really sure was possible. Olivia knew the day would come when she would no longer have the security and support of the university environment. A time when she would have to develop everything she had learned and gained through her university days. She wanted to pass on the skills she had learnt.

"But is it possible? What is the future for learning and what are the skills I might need to achieve my dream?”

Olivia pondered upon this question for some time.

"What if I could create dance through body mapping," she whispered, excited at this very thought. "Dance could travel. Adults, students, children, anyone interested in dance could learn any number of skills, routines and techniques. Dance education could be available at a distance and not only campus based. Dance would be accessible to the whole world at the click of a button.”

Olivia's excitement grew as she thought of the endless possibilities this scenario might offer her. She started work using her first idea. "If the dance floor was receptive to the dancer's steps, they could be mapped on to the computer screen," she muttered. "If sensors in the floor could map these steps and a camera could map the position of the body, I might just be able to do this," she exclaimed in great delight.

Olivia's idea was still in its embryonic form. It had such a long way to go, but she knew that she had the beginning of something exciting and bold, something, where no one had danced before.

\section{Chapter 2: The Challenge}

Olivia's enthusiasm was uncontainable.

"I have to show people what technology might be able to do for dance," she muttered.

"....only one problem, technology and dance....are they really able to collaborate.”

Olivia thought more and more about the sensual side of dance, the physicalness of it, the use of space and time.

"What can technology add to that," she asked, "without taking the pureness and beauty of it all away?"

Olivia and her friend Octavia discussed the issue for many an hour.

"Let's look at it from a physical perspective first,” reasoned Octavia. "Dance and technology are two distinct areas, poles apart, and you know technology could be a burden to the freedom we enjoy as dancers," she explained. "Why don't we explore technology through our dance and create a performance piece based on our fears. Once we have done this we can then look at the impact technology might have on our work from a different perspective."

Just at that moment Tyrone popped his head around the studio door.

"Forgive me for overhearing, but you know, you are looking at the essence of the argument back to front and upside down. Of course technology and dance are inherent within each other. Look! You start from your perspective and I'll start from mine and let's see what the two performances tell us about dance and technology, then we can have a critical discussion about the future of dance and technology based on something substantial."

“OK,” responded Olivia, we're up for that. "Six weeks and let's see what we have.”

The three dancers, three great friends, wandered off, full of ideas, ready to start planning, rehearsing and performing the two works yet wondering just what might emanate from it.

\section{Chapter 3: Billy's Surprise}

Billy watched Olivia and her friend travel gracefully across the studio. There was such beauty in their movement.

Olivia kneeled tightly on the floor whilst Octavia placed a typewriter on the honed muscles of her back.

"Hey 'Liv," shouted Billy across the studio, what you doing with a typewriter on your head?" 
Olivia moved suddenly as the typewriter crashed to the ground.

"Get out of here Billy," she shouted.

“Aw, sorry Liv,” whined Billy apologetically.

"It’s OK," Olivia answered smiling at her friend. "It was hurting my shoulder blades anyway."

"So what is it with the typewriter? A flat screen would have been much lighter," teased Billy.

"It's literally about the weight of technology on our shoulders as dancers. If technology is a burden to us in exploring our art, why use it?” Ocatvia continued. "I suppose you could call it a third collaborator," she explained, "but if that collaborator has no reason to be there, what's the point?"

“... Because that's our future,” Billy responded emphatically. "You have to go with it, no matter what you do or who you are."

"Do you?” Octavia was sceptical. "Do you really? Just because it is there doesn't mean you have to use it. There has to be a reason."

"I tell you what," Billy teased. "You tell me when your performance is and I'll film and edit it. Then if you would be happy for me to do so, I'll take it away and create something very different using that footage and technology. I'll show you why I think our futures and our learning futures particularly are reliant and in essence embraced in the arms of technology."

"It's a deal," shouted the girls in unison, "now get out of here!”

\section{Chapter 4: It's a Deal!}

"Virtual Environments. What do you mean?" Izzy shook her head confused to say the least.

"Well think about it," retorted Henry, somewhat frustrated at Izzy's lack of enthusiasm. "Design is all about looking at future needs. People don't always tell you what they want because they don't know. We have to create these scenarios for them. Think about it Izz. We can already create imaginary environments for a variety of needs, but what about our learning environment and future environments for educating designers and illustrators like you and me?"

"... and it's not just the learning environment at under- and postgraduate levels I suppose," retorted Izzy. She thought for a moment as the idea Charlie presented to her became clearer in her own mind.

"What about the workplace, our future working environment? The changes there will affect our own practice in the real world for most of our working life."

Charlie smiled. "Now you're with me Izz, so let's do something about it. You in the field of Illustration, whilst I develop the idea with some of the other students in garden, textile and interior design."
Izzy's enthusiasm had been ignited. Like a bullet waiting to be fired from a Colt 44 , she was ready to explode.

"What if I took the Strategy for Future Learning, which they must have somewhere, and turned it into a visual document. You know, a comic, picture book or graphic novel, something that was easily available and understood by people. I might be able to influence others thinking about the future, generate future possibilities in Illustrative education. What do you think Char?"

"Sounds great Izz," replied Charlie, secretly admiring Izzy's newly found enthusiasm.

"Meanwhile I'll delve into those environments for design education and the workplace we talked about." Charlie's mind was racing with ideas. He was on the starting grid and raring to go. "It's a deal. Let's go for it Izz," shouted Charlie excitedly.

"What NOW," Izzy enquired.

"No time like the present old girl,” responded Charlie with a glint in his eye. "Remember this. Today is tomorrow's future."

"Today.... is tomorrow's.... future," Izzy repeated slowly and quietly as she watched Charlie walk enthusiastically towards his goal, vying for pole position. "Today is tomorrow's future!"

\section{Chapter 5: First Day}

Sara pushed the refectory doors open with a huge sense of unease. A volley of noise hit her, knocking her back a step. Shouting, laughing, a cacophony of voices of different pitches and volumes emanated from the vast space in front of her. She stood alone, nervously wondering if she had made the biggest mistake of her life in coming to university to study.

Cat looked up. She noticed a tiny, pretty young thing standing at the refectory entrance looking as though at any minute she might bolt, like a young colt, back from wherever she came.

"Hi, I'm Cat!" Taking hold of Sara's arm she steered her towards a quiet corner. "Come on, it's OK, they won't bite, just a bit loud, honestly."

Sara looked around, her huge blue eyes like saucers peering from under her fringe.

"I'm not sure I know what all this university education is really all about," she confided in her new friend. "How will I manage my time? What will the study experience be like? How will it differ from sixth form? How will they want me to write essays? How will I manage and prioritise my time?"

"Whoa! Hold on a sec," Cat responded in the kind of calm, understated way only a third year student could. "We were all there once you know."

"But how different will things be here Cat? ....and it's not just now and for me, what about in the second and third years of my course?"

"Everyone feels like that at the beginning, although they might not show it." Cat was a 
comfort to Sara, so much so that a hint of a smile bought new life to Sara's face.

"Decades ago students worried about change and decades on it'll still be the same. Think what life for students might be like twenty, thirty or even fifty years from now. We'll be sitting by the fire, with our grandchildren on our laps telling tales of our time at Uni."

"Ooh, it wasn't like that in my day," mimicked Sara, showing Cat a mischievous side to her nature that she hadn't seen until now. "I love my grandparents sooooooo much," Sara continued, "but I often think about how much life has changed since they were eighteen. Technology, computers, e-books all now a basis for learning that they never had. Technology has driven our ability to learn and our access to and methods of learning in untold ways that they could only have dreamed about. But imagine Sara, sixty years from now, what will our grandchildren be doing on their first day at university? Will they even go to university to continue their education after school? Will there be any universities? How will they manage their study time and balance their social life whilst writing essays and learning new skills?"

"We won't ever know exactly, I don't suppose," chortled Cat. "But you know, even though we can't predict Academic Learning Futures, we can look at the possibilities technology might offer us and create scenario's for future learning with that in mind."

"... and we can start by managing our study time, balancing our social life, looking at appropriate methods of research and research skills and gaining an understanding of good essay writing," responded a more confident Sara.

"By Jove, the girl has got it!" Cat laughed whilst Sara even sniggered somewhat.

Sara was at ease with her newfound friend and had re-kindled an interest in learning futures, knowing that her immediate questions could, and would soon be answered.

"Come on," shouted Cat smiling at Sara, "let's move forward let's see what the future holds."

\section{CALF Findings}

The findings of the CALF project can be summarised under eight headings:

Employability: Learning and teaching in the future will make use of strong links with leading local and international employers.

Personalisation: Learning processes will be personalised to the needs and preferences of individual students with institutional support and guidance provided for the students' personal choice of learning technologies.

Openness: There will be increasing openness of learning resources, sharing of learning resources, networking across disciplines and blurring of institutional and disciplinary boundaries.

Quality: Provision of high quality learning environments, learning resources, student facilities and student accommodation will be a prominent characteristic of future learning and teaching.

Diversity: There are signals for increasing diversity in student demographics in the future with a greater number of mature, part-time, disabled and international students.

Mobility: Innovation, as well as internationalisation and globalisation trends, will support the increasing importance and availability of transnational education, the mobility of students and universities.

Non-state funding: The funding structure of higher education will change, with more emphasis placed upon private funding and student contributions, leading to a higher education sector that functions more like a private than a public sector.

Technological and pedagogical innovations: The development of new technological platforms and tools, and their increasing use, will create significant opportunities for the adaption of such technologies to meet educational needs. HE institutions will seek to improve their teaching and learning strategies as a result of demand for new and more flexible courses, methods of delivery and support services.

\section{Conclusions emanating from the CALF project}

- The design and implementation of the CALF project implies that its research model might benefit decision makers, policy planners, practitioners and learners in higher education.

- The model would seem to encourage users to plan from the future through visualising their institutions' long-term future and evaluating specific strategies in light of their existing aims and objectives.

- The model ensures both stakeholder participation and empowerment in a highly participatory process.

- The combined research methodologies allowed the discovery of trends and emerging possibilities whilst helping participants recognise both opportunities and hazards that might be invisible to traditional planning.

- Integrating learning futures activities into the higher education curriculum with lecturer support leads to high rates of participation and involvement in the process and awareness of its outcomes across the institution.

- There was noticeable evidence that the project highlighted the wealth of student expectation 
for the future of learning and their desire to be a part of that.

- The project created, explored and presented a variety of plausible 'alternative futures' for teaching and learning for future discussion.

\section{Recommendations for replicating the CALF implementation process for future projects might include:}

- Ensuring that the futures with which students are asked to engage are personal to them, i.e. are relevant to their own context, aspirations and ideas and are useable and actionable for the students in their own personal, academic and futures planning.

- Guarantee that the Learning Futures Process is supported by the students' institution both in terms of interaction and dialogue and in the institutions recognition of the students learning outcomes in the Learning Futures Process.

- Enabling the students vocalisation of their highest aspirations of what they wish to create, to 'make a difference' for both their own learning and for teaching and learning in the future.

- Creating and facilitating activities that empower students to reach beyond their current experiences.

- Presenting the Learning Futures scenarios as achievable, which will have an impact within a given time frame whilst enabling the students to believe that they can create change and make things happen.

This rich picture of future learning and teaching highlighted by CALF was developed as a result of the development and implementation of a set of innovative research methods. The data collection within CALF was guided by a research model called Learning Futures (see above). Developed specifically for the project by National Teaching Fellow Prof. Gilly Salmon, the model structures a process for a pro-active application of analytical and creative skills for envisaging the future of $\mathrm{HE}$. The outcome of the application is an understanding of what may happen in the future of teaching and learning in $\mathrm{HE}$ and a clear, shared commitment to creating the preferred future for higher education institutions (HEI).

\section{Responses to the CALF Project}

\section{Staff responses (anonymous)}

"I think the information drawn from CALF actually substantiates the concept of looking at learning futures from a creative arts perspective rather than the standard model adopted by red brick more academically focused institutions. It will make a significant impact. As we look towards alternative forms of delivery, and pilot various forms with courses perhaps more suited to the existing methods and tools, I feel there is an increasing gap in the type of resources available for physical making and studio based practice. Perhaps this is an area we can focus upon, and attempt to gain funding."

"The invitation for our course to contribute to the CALF project was filled with possibilities. The idea of opening up a space to consider learning futures was exciting for staff and students. What could teaching look like in the future? How could we make a significant contribution and create meaningful developments?

However, I do feel that language-based subjects, like professional writing or journalism, and maybe to a lesser extent performing arts, by their nature, easily translate across digital modes of communication, and therefore lent themselves to the project. The development and making of the physical image/artefact presents a different range of experiences that necessitate different consideration. One problem we had to address early on in the project was the nature of 'making' of physical artefacts, which by their nature don't lend themselves to digital production or mediation. Here, the learning process involves a 'hands-on' crafting of materials with tutor support.”

"We must aim towards creating a specific frame for collaboration (a frame that can lie outside particular disciplines) creating a shared understanding as a starting point.”

"We should recognise these collaborations as a new art form: The Recognition of Interdisciplinary and Trans-disciplinary Potential.”

"Skills sharing needs time - to familiarize, experiment, play, develop. Collaborative models give time for this.”

"If a further CALF-style project was to be run at UCF, it would potentially be very fruitful if it addressed the very different nature of learning and teaching in relation to art and design practices that involve hand-crafted artefacts."

"The opportunity to participate in the CALF project for my department has been invaluable in helping us to understand how we will develop our understanding of enhancing performance based subject though technology. Our participation so far has been to provide technical expertise, equipment, staff and resourcing to the technology event held earlier this year. We devised a series of physical computing projects throughout the latter half of the 
project which we presented to a select group of staff and students at our Dartington performance campus, as part of a week long event. The reception was better than expected with a good degree of engagement from all participants, including some of the students incorporating the technology into a number of unique performances."

"From this event we began to plan a follow-up session with the students for the following academic year.”

"Our future engagement is likely to be more integrated and accessible as we aim to provide constant access to technology within our newly constructed performance centre.”

"Without the CALF project we may well have not reached this level of understanding and engagement."

\section{Student response (anonymous)}

"Technology and artistic practices should enhance one another. It is necessary to consider collaboratively developing a common understanding between disciplines”

\section{Reflections}

The Learning Futures model was implemented in 44 collaborative workshops for imagining the future of learning and teaching. Data was collected using a combination of three research methods: scenario development, maximum difference scaling surveys and cognitive mapping interviews. Data was collected from 320 students from UCF and UoL and from 209 contributors from the wider research and teaching communities. A range of literary sources and policy reports reporting ideas about the future of education were analysed.

The findings were widely disseminated across a community of interest through conference presentations and workshops, the newsletters and web portals of the two partnering institutions, the project blogs (see Knight, Feb 2016; University of Leicester, Feb 2009-Oct 2011) and a variety of other web-based dissemination channels.

\section{Achievements}

- The many achievements throughout CALF ensured that it met its planned aims and objectives and delivered its expected outcomes. The added value of the project's deliverables lie in:

- The development of models of learning futures.

- Designing frameworks to encourage learners' involvement in the planning, re-shaping and assessment of learning and technologies.
- Developing the capacity of students and staff at both institutions to imagine and analyse the future of learning.

- Informing the planning of new structures for the delivery of UCF's courses and new strategies for teaching and learning at both institutions.

\section{Legacies}

Legacies at Falmouth University emanating from the CALF project include:

- Dance technology becoming an integral part of the dance curriculum within the newly formed dance spaces in the performing arts centre. This included all the technology hardware required to build on the work achieved throughout the project.

- Greater emphasis to be placed on crosscurricular projects and development.

- The creation of a specific post to develop futures ideas and work.

- Creating alliances with other research universities - (such as ADaPT, the Association for Dance and Performance Telematics, which includes the University of California-Irvine, Ohio State University, Arizona State University, University of Utah Florida State University and the University of Wisconsin).

- Ensuring availability of access to facilities. A PLAY ROOM or interactive Space/Performance Technologies Centre, such as an "Active Space Environment" to be developed in conjunction with The Learning Space and Social Media including Twitter and Facebook, which need to be fun to encourage student usage.

- The recognition of two distinct uses of technology in arts practice and their potential for cross-fertilisation, 1 . To gather data and document knowledge and 2. For creative play and experimentation

- The creation of a CALF archive for future research. 


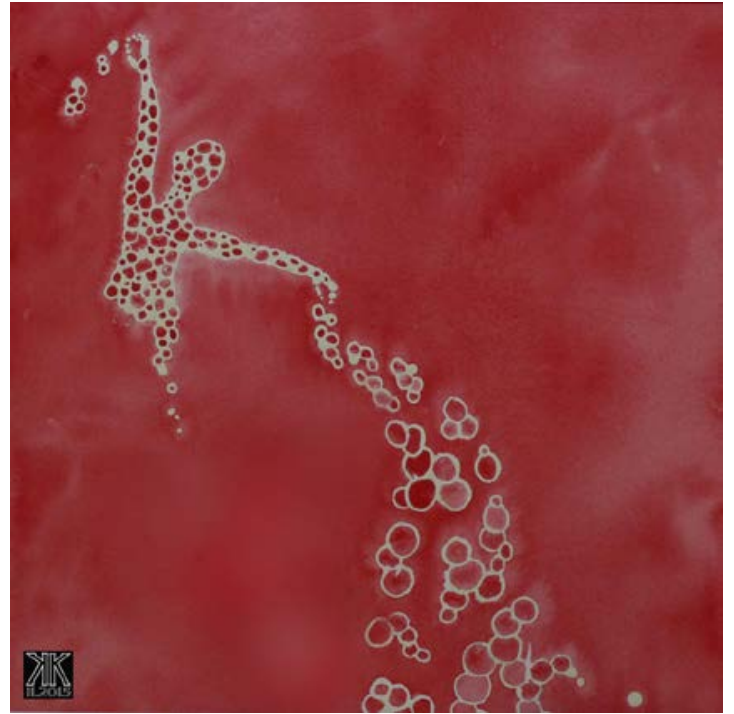

Image 2: "Bubbles". Dance experimentation using 'Processing' technology. An illustrative response to a dance/technology workshop by Karenanne Knight.

\section{References}

Romenska, S., Knight, K., Cane, R., Mukherjee, J., George, A. \& Salmon, G. (2011), Creating Academic Learning Futures, (Final report to National Teaching Fellowship Scheme, UK). Retrieved from https://www2.le.ac.uk/departments/beyonddistance-researchalliance/projects/calf/CALF\%20NTFS-FinalReport.pdf/view

Knight, Karenanne (Feb 2016) The story of CALF [Web log]. Retrieved from https://calf2016.wordpress.com

University of Leicester, (Feb 2009-Oct 2011). Creating Academic Learning Futures [Web log]. Retrieved from https://calfutures.wordpress.com/

\section{Acknowledgements}

This paper recognizes the work of Dr. Sandra Romenska and her input as research associate into the final project report (Romenska et al., 2011) from which elements of the paper have been taken.

\section{Research Profile}

Dr. Karenanne Knight is the author of The Picture Book Maker: The Art of the Picture Book Writer and Illustrator (Trentham Books/IOE Press, 2014). She has also authored and illustrated several picture books for children and regularly writes papers for academic journals as well as presentations for various conferences on a national and international platform. She divides her time between her academic work at Falmouth University; writing, Illustrating and designing children's, adult and academic books for a variety of publishers; design and logo/branding work for festivals, commercial and corporate clients, and completing commissions; residences and collaborations with clientele such as the British Army; Truro Cathedral; The Royal Ballet; Great Western Railways; The Rt. Hon. Dominic Grieve at the Houses of Parliament and Buckinghamshire and Milton Keynes Fire and Rescue. She exhibits her work nationally and has pieces in collections worldwide. 